\title{
Behavioral sensitization to cocaine: cooperation between glucocorticoids and epinephrine
}

\author{
Inge E. M. de Jong • Peter J. Steenbergen • \\ E. Ronald de Kloet
}

Received: 31 August 2008 / Accepted: 19 February 2009/Published online: 6 March 2009

(C) The Author(s) 2009. This article is published with open access at Springerlink.com

\begin{abstract}
Rationale Stressful life experiences facilitate responsiveness to psychostimulant drugs. While there is ample evidence that adrenal glucocorticoids mediate these effects of stress, the role of the sympatho-adrenal system in the effects of psychostimulants is poorly understood.

Objectives The present study investigated the role of the two adrenal stress hormones, corticosterone and epinephrine, in sensitization to the locomotor stimulant effects of cocaine. Materials and methods The DBA/2 mouse strain was used, as behavioral sensitization in this strain critically depends on adrenal hormones. Animals were subjected to adrenalectomy ("ADX", surgical removal of the adrenals) or SHAM surgery, and ADX mice were given replacement of epinephrine $(5 \times$ $10^{-3} \mathrm{mg} / \mathrm{kg}$ subcutaneously (s.c.) just prior to each drug administration), corticosterone (20\%, s.c., pellet), or both. Mice were subjected to a cocaine sensitization regimen (15.0 $\mathrm{mg} / \mathrm{kg}$ cocaine on nine consecutive days followed by a $7.5 \mathrm{mg} / \mathrm{kg}$ cocaine challenge after a 5-day withdrawal).

Results In agreement with our previous observations, ADX prevented initiation and expression of cocaine-induced locomotor sensitization. Whereas neither corticosterone nor epinephrine alone were sufficient to reverse the ADX effect, both hormones were necessary to fully restore initiation and retention of sensitization to levels observed in SHAM animals.

I. E. M. de Jong · P. J. Steenbergen · E. R. de Kloet Medical Pharmacology,

Leiden/Amsterdam Center for Drug Research and Leiden

University Medical Center, Gorlaeus Laboratories,

Einsteinweg 55, P.O. Box 9502, 2300 RA Leiden,

The Netherlands

Present address:

I. E. M. de Jong $(\square)$

In Vivo Neurobiology, H. Lundbeck A/S,

Ottiliavej 9, 2500 Valby, Denmark

e-mail: IDJ@Lundbeck.com
\end{abstract}

Conclusions The present findings indicate that corticosterone and epinephrine cooperate to facilitate behavioral responsiveness to cocaine. These data emphasize that in addition to the hypothalamic-pituitary-adrenal axis, the sympathetic nervous system plays a critical role in psychostimulant sensitivity.

Keywords Corticosterone · HPA axis · Adrenalectomy · Sympathetic nervous system · Psychostimulant - Stress · Brain - Locomotion

$\begin{array}{ll}\text { Abbreviations } \\ \text { ADX } & \text { Adrenalectomy } \\ \text { ANOVA } & \text { Analysis of variance } \\ \text { ANS } & \text { Autonomic sympathetic nervous system } \\ \text { CORT } & \text { Corticosterone } \\ \text { COC } & \text { Cocaine } \\ \text { EPI } & \text { Epinephrine } \\ \text { GR } & \text { Glucocorticoid receptor } \\ \text { HPA axis } & \text { Hypothalamic-pituitary-adrenal axis } \\ \text { RIA } & \text { Radioimmunoassay } \\ \text { SAL } & \text { Saline } \\ \text { SHAM } & \text { Sham surgery }\end{array}$

\section{Introduction}

It is well known that stress, resulting in activation of the hypothalamic-pituitary-adrenal axis (HPA-axis) and the autonomic sympathetic nervous system (ANS; De Kloet et al. 2005), can increase sensitivity to the behavioral and reinforcing effects of psychostimulant drugs, a phenomenon known as behavioral sensitization (Piazza and Le Moal 1998; Goeders 2003). Studies in laboratory rodents have demonstrated that stress facilitates acquisition and relapse of psychostimulant self-administration (Piazza et al. 1990; 
Goeders and Guerin 1994; Haney et al. 1995; Tidey and Miczek 1997) and enhances sensitivity to the locomotor stimulant properties of these drugs (Herman et al. 1984; Sorg and Kalivas 1991; Deroche et al. 1995; Haile et al. 2001; Lepsch et al. 2005).

A wealth of data indicates that adrenal glucocorticoids, the output hormones of the HPA-axis, mediate the effects of stress on psychostimulant responsiveness (Marinelli and Piazza 2002; Goeders 2002; Deroche-Gamonet et al. 2003; De Jong and De Kloet 2004) primarily via their actions in the mesencephalic dopamine system (Piazza and Le Moal 1996). By contrast, the role of the ANS in psychostimulant sensitivity has received little attention. This is surprising since catecholamines (epinephrine, norepinephrine) are rapidly released into the general circulation during stress and in response to psychostimulant administration (Chiueh and Kopin 1978). Although the catecholamines are not likely to cross the blood-brain barrier due to their polar structure (Weil-Malherbe et al. 1959), substantial evidence indicates that peripheral epinephrine can alter brain function and behavior indirectly by activating vagal afferents to the central nervous system (Gold and Van Buskirk 1975; Borrell et al. 1983; Sternberg et al. 1985; Miyashita and Williams 2006). Indeed, it has been shown that in addition to their independent actions, the HPA and ANS components of the stress response can interact to regulate behavior (Borrell et al. 1984; Roozendaal et al. 1996).

We have previously identified a mouse strain, the DBA/2 strain, in which sensitization to the locomotor stimulant effects of cocaine is critically dependent on adrenal hormones (De Jong et al. 2007). Interestingly, whereas surgical removal of the adrenals (adrenalectomy, "ADX") prevented initiation and expression of psychomotor sensitization, replacement of corticosterone to concentrations similar or even higher than those induced by stress was not sufficient to fully reverse the effects of ADX (De Jong and De Kloet 2009). Similarly, it has recently been reported that glucocorticoids are necessary, but not sufficient, to restore the effects of stress on escalation of cocaine self-administration (Mantsch and Katz 2007) and on morphine-induced conditioned place preference (DerAvakian et al. 2006) in ADX rats. In addition, there is considerable controversy in literature regarding the necessity of adrenal glucocorticoids in psychostimulant-induced behavioral sensitization (Rivet et al. 1989; Badiani et al. 1995; Pauly et al. 1993; Prasad et al. 1996; Przegalinski et al. 2000). Additional evidence for a dissociation between corticosterone secretion and behavioral sensitization comes from a study by Schmidt et al. (1999) who showed that sensitization of the corticosterone response to amphetamine was neither necessary nor sufficient for sensitization of the psychomotor response to the psychostimulant to occur. Collectively, these findings suggest that adrenal glucocorticoids may not be "the sole players on the scene." In view of our findings with ADX, we propose an additional role for the adrenal catecholamine epinephrine (De Jong et al. 2007).

In the present study, we have therefore investigated the role of adrenal glucocorticoids and epinephrine in sensitization to the locomotor stimulant effects of cocaine in the DBA/2 strain, which has been demonstrated to be highly susceptible to the impact of stress on drug responsiveness (Cabib et al. 2000). Animals were adrenalectomized or SHAM-operated, and ADX mice were given replacement of corticosterone (through release from a s.c. implanted $20 \%$ pellet $)$, epinephrine $\left(5 \times 10^{-3} \mathrm{mg} / \mathrm{kg}\right.$, s.c., prior to each drug administration), or both. These doses were chosen based on previous findings (Van den Buuse et al. 2004) and pilot studies. The data show that the HPA-axis and the ANS act in a coordinate fashion to facilitate behavioral sensitization of $\mathrm{DBA} / 2$ mice to cocaine.

\section{Materials and methods}

\section{Animals}

Male DBA/2 Rj mice were obtained from Janvier (Le Genest Saint Isle, France) at the age of 8 weeks. Mice were housed in groups of four in perspex cages $(35 \times 19 \times 14 \mathrm{~cm})$ with food and water available ad libitum at a 12-h light-dark cycle (lights on at 7 A.M.) in a temperature- $\left(21 \pm 1^{\circ} \mathrm{C}\right)$ and humidity$(55 \pm 5 \%)$ controlled room. Surgery was performed 2 weeks after arrival in the animal facility. Animal experiments were performed according to the principles of laboratory animal care as specified in the Guidelines for the Care and Use of Mammals in Neuroscience and Behavioral Research (National Research Council 2003) and in accordance with the EC Council Directive of November 1986 (86/609/EEC). Experiments were approved by the local Committee for Animal Health, Ethics and Research of Leiden University.

\section{Experimental design}

Animals were either adrenalectomized (ADX) or SHAMoperated. Replacement therapies consisted of corticosterone (ADXcort), epinephrine (ADXepi), or both (ADXcort+epi). Mice were administered saline (SAL) or cocaine (COC) during the treatment phase of the sensitization paradigm, resulting in ten treatment groups: SHAM (SAL/COC), ADX (SAL/COC), ADXcort (SAL/COC), ADXepi (SAL/COC), and ADXcort+epi (SAL/COC).

\section{Surgery}

Animals were individually housed 1 day prior to surgery. The cages were transported to the operating room on the morning of the surgery where mice were allowed to recover 
from transportation for $2 \mathrm{~h}$. Inhalation anesthesia consisted of a mixture of isoflurane (3 1/min), $\mathrm{N}_{2} \mathrm{O}(0.8 \mathrm{l} / \mathrm{min})$, and $\mathrm{O}_{2}(0.4 \mathrm{l} / \mathrm{min})$. Adrenalectomy was performed via the dorsal route as described previously (De Jong et al. 2007). SHAM animals were treated similarly with the exception of the actual removal of the adrenals. After surgery, all animals were given free access to $0.9 \% \mathrm{NaCl}$ in addition to normal drinking water. The sensitization paradigm was started following a recovery period of 1 week. Animals were single-housed during the entire paradigm.

\section{Drugs}

Cocaine hydrochloride (BUFA Pharmaceuticals B.V., Uitgeest, The Netherlands) was dissolved in sterile saline and administered intraperitoneally (i.p.) in a dosage of 7.5 or $15.0 \mathrm{mg} / \mathrm{kg}$. Corticosterone pellets $(100 \mathrm{mg} ; w \times h, 9 \times$ $2 \mathrm{~mm}$ ) consisted of $20 \%$ corticosterone (ICN Biomedicals Inc, Aurora, Ohio, USA) in cholesterol vehicle (cholesterol 95\% stabilized, Acros Organics, Geel, Belgium) and were implanted subcutaneously in the flank of the animal 1 day prior to the onset of the sensitization paradigm. Epinephrine ((-)-epinephrine(+)-bitartrate salt; Sigma-Aldrich Chemie B.V., Zwijndrecht, The Netherlands) was dissolved in

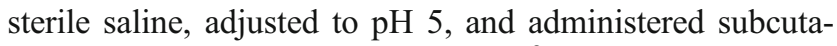
neously (s.c.) in a dosage of $5 \times 10^{-3} \mathrm{mg} / \mathrm{kg}$ just prior to drug treatment on days 1-9, 14, and 15. Control groups were implanted with $100 \%$ cholesterol pellets and received equal volumes of saline instead of cocaine or epinephrine.

\section{Sensitization paradigm}

The sensitization paradigm consisted of a treatment phase (days 1-9), a withdrawal interval (days 10-14), a saline challenge (day 14), and two cocaine challenges (days 15 and 21). The treatment phase consisted of i.p. injections of $15.0 \mathrm{mg} / \mathrm{kg}$ cocaine (COC) or saline (SAL) on nine consecutive days and locomotion was measured on days 1 , 5, and 9. On these days, animals received the treatment in the test setting, whereas on the remaining days, injections were given in the home cage. The treatment period was followed by a withdrawal interval of 5 days (no treatment). On the last day of the withdrawal interval (day 14), all animals received a saline challenge, and on day 15, all animals received a $7.5 \mathrm{mg} / \mathrm{kg}$ cocaine challenge. To investigate drug responsiveness in absence of epinephrine, animals were re-challenged with $7.5 \mathrm{mg} / \mathrm{kg}$ cocaine 1 week after the initial cocaine challenge (day 21) without prior epinephrine substitution. For this day, only data of cocainetreated mice are presented, as the saline-treated groups received cocaine for the second time and can therefore no longer be considered proper controls for an acute cocaine response. All injections were given 2 to $5 \mathrm{~h}$ after lights on.
Measurement and analysis of locomotor activity

All behavioral tests (days 1, 5, 9, 14, 15 and 21) were performed in the room where animals were housed. Mice were placed in a test cage (same type and size $(35 \times 19 \times 14 \mathrm{~cm})$ as the home cage) containing a standardized amount of sawdust, covered with a perspex lid. Following a 2-h habituation period, animals were injected and activity was monitored on video for $30 \mathrm{~min}$. At the end of this period, a blood sample was taken from the tail vein for endocrine measurements and the animals were returned to their home cage. Video images were digitized and analyzed using Ethovision Videotracking, Motion Analysis \& Behavior Recognition System version 1.96 ("VTMAS", Noldus Information Technology B.V., Wageningen, The Netherlands). The position of the animal was sampled five times per second. Locomotion was defined as movement with a minimal distance of $2 \mathrm{~cm}$. Data are represented in total distance moved $(\mathrm{cm})$ over the entire treatment period.

\section{Corticosterone assay}

Blood samples were taken from the tail vein by a small incision with a razor blade 30 min after drug treatment on test days 1, 5, 9, 14, and 15 and collected in small EDTAcoated tubes (Microvette DB 200 K3E, Sarstedt, Nümbrecht, Germany). On day 21, animals were killed $30 \mathrm{~min}$ after treatment and trunk blood was collected in large EDTA-coated tubes (tube $10 \mathrm{ml}, 95 \times 16.8 \mathrm{~mm}, \mathrm{~K} 3 \mathrm{E}$, Sarstedt). Plasma was obtained by centrifugation at $13,000 \mathrm{rpm}$ for $20 \mathrm{~min}$ at $4^{\circ} \mathrm{C}$ and subsequently stored at $-20^{\circ} \mathrm{C}$. Corticosterone concentrations were determined by in duplo measurement using a radioimmunoassay (RIA) kit from MP Biomedicals according to the protocol provided by the manufacturer (Corticosterone double antibody ${ }^{125} \mathrm{I}$ RIA kit, MP Biomedicals, Asse-Relegem, Belgium). All samples were analyzed in one assay to exclude inter-assay variability. ADX effectively attenuated corticosterone release to basal concentrations.

\section{Statistics}

Statistical analysis was performed using SPSS for Windows software (release 7.5, SPSS Benelux B.V., Gorinchem, The Netherlands). Overall locomotor activity and corticosterone data were subjected to repeated measures analysis of variance (ANOVA) with three between-subject factors (surgery, substitution, and treatment) and one withinsubject factor (test day). Subsequent analyses were performed per test day: three-factor ANOVA for surgery, substitution, and treatment. When statistical significance was revealed, post hoc tests were performed (least significant difference (LSD) or, for within subject comparison, paired $t$ 
test). Differences were considered statistically significant when $p<0.05$.

\section{Results}

Effect of corticosterone and epinephrine on behavioral sensitization in ADX mice

Main effects were found for treatment, surgery, substitution, day, and interactions between these factors $(F \text { (treatment) }]_{1,126}=$ $39.878, p<0.001 ; F$ (surgery) ${ }_{1,126}=6.667, p<0.05 ; F$ (substitution $)_{3,126}=3.006, p<0.05 ; F(\text { day })_{5,630}=28.002, p<0.001$; $F(\text { day } \times \text { substitution })_{15,630}=1.726, p<0.05$, and $F($ day $\times$ treatment $\left.)_{5,630}=14.038, p<0.001\right)$.

Figure 1 depicts locomotor responses of the SHAM (SAL/ COC), ADX (SAL/COC), ADXcort (SAL/COC), ADXepi (SAL/COC), and ADXcort+epi (SAL/COC) groups on days 1 and 5 of the treatment period. Corticosterone replacement via the $20 \%$ pellet reduced the initial cocaine response $(p<0.001$ vs. SHAM, $p<0.05$ vs. ADX and ADXepi), while there was a strong tendency for epinephrine to reverse this effect (ADXcort vs. ADXcort+epi, $p=0.060$ ). In addition, cocaine responses on day 1 were highest in the SHAM group $(F \text { (treatment })_{1,150}=13.131, p<0.001 ; F$ (surgery $)_{1,150}=2.342, p=0.128 ; F(\text { substitution })_{3,150}=0.317, p=$ 0.813 , post hoc: at least $p<0.05$ vs. all other treatment groups).

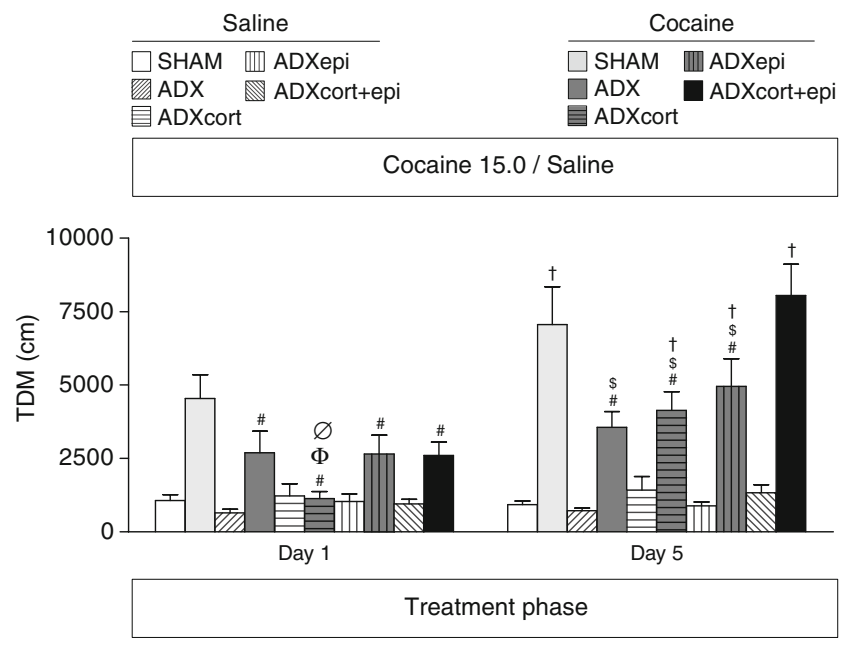

Fig. 1 Initiation of behavioral sensitization. Locomotion in response to treatment on days 1 and 5 of the treatment period in which mice received daily administration of cocaine $(15.0 \mathrm{mg} / \mathrm{kg})$ or saline. Animals were SHAM-operated or adrenalectomized $(A D X)$, and ADX mice received either no substitution or replacement with corticosterone (ADXcort), epinephrine (ADXepi), or both $(A D X c o r t+e p i)$. Data are represented in average total distance moved $(T D M, \mathrm{~cm}) \pm \mathrm{SEM}, n=$ 7-9 (saline) or 17-24 (cocaine) animals/group. ${ }^{*}$ at least $p<0.05$ vs. SHAM, ${ }^{\Phi} p<0.05$ vs. ADX, ${ }^{\varnothing} p<0.05$ vs. ADXepi, ${ }^{\$}$ at least $p<0.01$ vs. ADXcort+epi (LSD), ${ }^{\dagger}$ at least $\mathrm{p}<0.05$ vs. day 1 (paired $t$ test)
As described previously (De Jong et al. 2007), SHAM mice displayed an increase in drug responsiveness during the treatment period (day 5 vs. day $1, p<0.05$, paired $t$ test), whereas this was prevented by $\operatorname{ADX}(p=0.191$, paired $t$ test). Furthermore, cocaine responses on day 5 were reduced in ADX when compared to SHAM mice $(p<0.01)$. Coreplacement of corticosterone and epinephrine fully restored initiation of sensitization (day 5 vs. day $1, p<0.001$, paired $t$ test) and drug responses on day 5 to the level observed in SHAM mice. The ADXcort and ADXepi groups also displayed an increase in cocaine responsiveness from day 1 to day 5 ( $p<0.01$, paired $t$ test), but drug responses on day 5 were not different from those of ADX mice and lower than in the SHAM and ADXcort+epi groups $(F \text { (treatment })_{1,142}=$ 41.974, $p<0.001 ; F$ (surgery) $)_{1,142}=2.870, p=0.093 ; F$ (substitution $)_{3,142}=2.373, p=0.073$, post hoc: at least $p<0.05$ vs. SHAM and ADXcort+epi).

Drug responses on day 9 of the treatment period showed a similar group distribution and were not further enhanced when compared to day 5 , indicating that behavioral sensitization develops during the first half of the treatment period (SHAM: 7,508 $\pm 1,009$; ADX: 4,193 \pm 725 ; ADXcort: 5,641 \pm 747 ; ADXepi: 5,718 \pm 898 ; ADXcort+epi: 6,252 $\pm 1,030$ ). On this day, there was a tendency for cocaine responses of ADXcort and ADXepi mice to exceed those of ADX mice, but this did not reach statistical significance $(p=0.208$ and $p=0.195$ vs. ADX, respectively) ( $F$ (treatment $)_{1,139}=43.477, p<0.001$; $F(\text { surgery })_{1,139}=2.390, p=0.125 ; F(\text { substitution })_{3,139}=0.425$, $p=0.735)$.

Figure 2 depicts locomotor responses to the first cocaine challenge on day 15. Cocaine-treated SHAM mice displayed hyperresponsiveness to the $7.5 \mathrm{mg} / \mathrm{kg}$ cocaine challenge $(p<$ 0.01 vs. SHAM/SAL), whereas this was not observed in ADX mice receiving no substitution or either corticosterone or epinephrine alone. By contrast, sensitization was restored in ADX mice receiving co-replacement of corticosterone and epinephrine (ADXcort+epi COC vs. SAL, $p<0.05$ ). Furthermore, drug responses of cocaine-treated SHAM and ADXcort +epi mice were higher than of $\mathrm{ADX}$ and ADXepi mice (at least $p<0.05$, except SHAM/COC vs. ADXepi/COC, $p=0.078)$, but not different from ADXcort mice [F(treatment $)_{1,138}=8.182, p<0.01 ; F(\text { surgery })_{1,138}=0.644, p=0.424$; $\left.F(\text { substitution })_{3,138}=1.401, p=0.245\right)$. Similar group differences were observed on day 21 , when cocaine-treated mice were re-challenged with $7.5 \mathrm{mg} / \mathrm{kg}$ cocaine without prior epinephrine substitution (Fig. 3). SHAM and ADXcort+epi mice displayed cocaine responses higher than of ADX and ADXepi mice (at least $p<0.05$ ), but not different from the $\mathrm{ADX}$ cort mice $\left(F\right.$ (treatment) ${ }_{1,139}=6.156, p<0.05$;

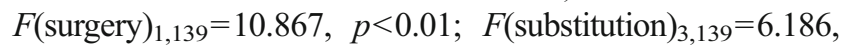
$p<0.01)$.

Remarkably, responses to the saline challenge on day 14 showed a similar distribution as to the cocaine challenges on 


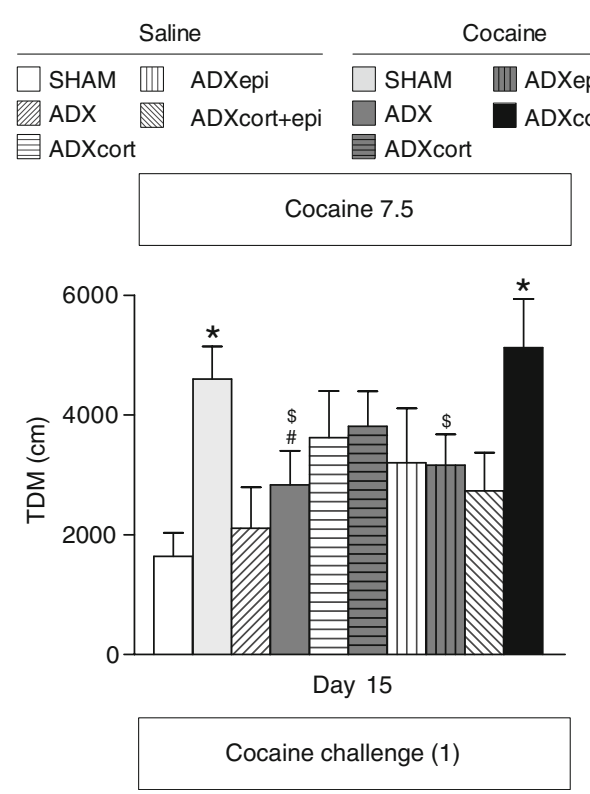

Fig. 2 Expression of behavioral sensitization (day 15). Locomotion in response to the $7.5 \mathrm{mg} / \mathrm{kg}$ cocaine challenge on day 15 . Animals were SHAM-operated or adrenalectomized $(A D X)$, and ADX mice received either no substitution or replacement with corticosterone (ADXcort), epinephrine (ADXepi), or both (ADXcort + epi). Previously, mice received daily administrations of $15.0 \mathrm{mg} / \mathrm{kg}$ cocaine or saline (days $1-$ 9), followed by a 5-day withdrawal interval and a saline challenge (day 14). Data are represented in average total distance moved (TDM, cm) \pm SEM, $n=7-11$ (saline) or 17-22 (cocaine) animals/group. *at least $p<0.05$ vs. SAL, ${ }^{*} p<0.05$ vs. SHAM, \$at least $p<0.05$ vs. ADXcort+epi (LSD)

days 15 and 21, being higher for cocaine-treated SHAM, ADXcort, and ADXcort+epi mice than for ADX and ADXepi mice (SHAM: 2,496 \pm 259 ; ADX: 1,429 \pm 114 ; ADXcort: 2,597 \pm 208 ; ADXepi: 1,477 \pm 154 ; ADXcort+epi: $2,582 \pm$ 239). A significant effect of treatment was only found in the SHAM group $(F \text { (treatment })_{1,139}=3.130, p=0.079 ; F$ (surgery) $)_{1,139}=2.969, p=0.087 ; F$ (substitution $)_{3,139}=4.062, p<$ 0.01 , post hoc: SHAM COC vs. SAL, $p<0.05$ ). Locomotor responses to the saline challenge were, however, markedly lower than to the cocaine challenge on day 15 , indicating that conditioned responsiveness cannot have accounted for the full sensitization as observed in response to the cocaine challenges.

Effect of ADX and hormone replacement on plasma corticosterone

Table 1 shows the effects of ADX and hormone replacement on plasma corticosterone concentrations $30 \mathrm{~min}$ after treatment on days 1, 5, 9,14, and 15. Main effects were found for treatment, surgery, substitution, day, and interactions between these factors $(F \text { (treatment })_{1,108}=30.233, p<0.001 ; F$ (surgery $)_{1,108}=94.276, \quad p<0.001 ; F$ (substitution) $)_{3,108}=129.940$, $p<0.001 ; F(\text { day })_{5,540}=141.546, p<0.001 ; F($ day $\times$ substitu-

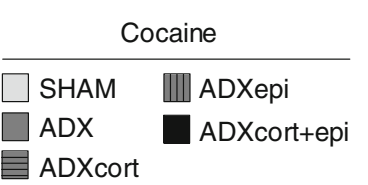

Cocaine 7.5

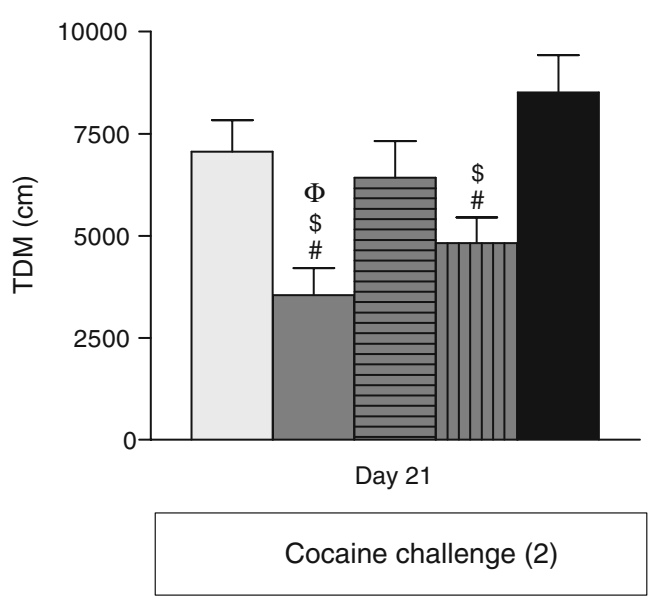

Fig. 3 Expression of behavioral sensitization (day 21). Locomotion of cocaine-treated mice in response to the second $7.5 \mathrm{mg} / \mathrm{kg}$ cocaine challenge on day 21. On this day, epinephrine replacement was omitted. Previously, SHAM-operated and ADX mice receiving either no substitution or replacement with corticosterone (ADXcort), epinephrine $(A D X e p i)$, or both $(A D X c o r t+e p i)$ were given daily administrations of $15.0 \mathrm{mg} / \mathrm{kg}$ cocaine or saline (days 1-9), followed by a 5-day withdrawal interval, a saline challenge (day 14), and a 7.5-mg/ $\mathrm{kg}$ cocaine challenge (day 15). Data are represented in average total distance moved $(T D M, \mathrm{~cm}) \pm \mathrm{SEM}, n=7-12$ (saline) or $17-22$ (cocaine) animals/group. ${ }^{\#} p<0.01$ vs. SHAM, ${ }^{\Phi} \mathrm{p}<0.01$ vs. ADXcort, $\$_{p<0.001 \text { vs. ADXcort }+ \text { epi (LSD) }}$

tion) ${ }_{15,540}=105.773, p<0.001$; and $F($ day $\times$ surgery $\times$ treatment $)_{5,540}=4.936, p<0.001$ ).

Corticosterone concentrations were attenuated in the ADX and ADXepi groups compared to the SHAM group on all test days (at least $p<0.01$, except ADX/SAL day 1: $p=0.058$; day 14: $p=0.073$; ADXepi/SAL day 1: $p=0.055$; day 14: $p=$ 0.070 vs. SHAM/SAL). Cocaine-treated SHAM mice exhibited enhanced corticosterone secretion on day 5 compared to day 1 of the treatment period ( $p<0.001$, paired $t$ test), with no further increase on day 9 , indicating that also endocrine sensitization develops during the first half of the treatment period. In addition, corticosterone secretion in response to the saline challenge on day 14 was augmented in SHAM/COC mice $(p<0.001$ vs. SHAM/SAL). A similar effect was observed in response to the cocaine challenge on day 15 , but this did not reach statistical significance ( $p=$ 0.248). In two previous studies with the exact same paradigm, however, significantly augmented corticosterone secretion was demonstrated in cocaine-treated SHAM mice on day 15 , suggesting that sensitization of the corticosterone 
Table 1 Plasma corticosterone concentrations

\begin{tabular}{|c|c|c|c|c|c|c|}
\hline & & \multirow[t]{2}{*}{ Day 1} & \multirow[t]{2}{*}{ Day 5} & \multirow[t]{2}{*}{ Day 9} & \multirow{2}{*}{$\frac{\text { Day } 14}{\text { Saline challenge }}$} & \multirow{2}{*}{$\begin{array}{l}\text { Day } 15 \\
\text { Cocaine challenge } 1\end{array}$} \\
\hline & & & & & & \\
\hline \multirow[t]{2}{*}{ SHAM } & SAL & $87 \pm 14$ & $92 \pm 20$ & $125 \pm 30$ & $66 \pm 11$ & $182 \pm 13$ \\
\hline & $\mathrm{COC}$ & $162 \pm 12 *$ & $313 \pm 15^{*, \dagger}$ & $307 \pm 20 *$ & $140 \pm 16^{*}$ & $209 \pm 22$ \\
\hline \multirow[t]{2}{*}{ ADX } & SAL & $14 \pm 3$ & $17 \pm 7^{\#}$ & $28 \pm 10^{\#}$ & $31 \pm 11$ & $33 \pm 12^{\#}$ \\
\hline & $\mathrm{COC}$ & $15 \pm 3^{\#}$ & $26 \pm 5^{\#}$ & $36 \pm 7^{\#}$ & $32 \pm 5^{\#}$ & $33 \pm 6^{\#}$ \\
\hline \multirow[t]{2}{*}{ CORT } & SAL & $538 \pm 32^{\#, \Omega}$ & $170 \pm 6^{\#, \Omega}$ & $112 \pm 9^{\Omega}$ & $75 \pm 3^{\Omega}$ & $84 \pm 9^{\#, \Omega}$ \\
\hline & $\mathrm{COC}$ & $500 \pm 24^{\#, \Omega}$ & $179 \pm 6^{\#, \Omega}$ & $130 \pm 8^{\#, \Omega}$ & $86 \pm 5^{\#, \Omega}$ & $92 \pm 9^{\#, \Omega}$ \\
\hline \multirow[t]{2}{*}{ EPI } & SAL & $11 \pm 2$ & $20 \pm 6^{\#}$ & $22 \pm 6^{\#}$ & $30 \pm 9$ & $30 \pm 10^{\#}$ \\
\hline & $\mathrm{COC}$ & $15 \pm 2^{\#}$ & $29 \pm 4^{\#}$ & $39 \pm 6^{\#}$ & $36 \pm 6^{\#}$ & $38 \pm 6^{\#}$ \\
\hline \multirow[t]{2}{*}{$\mathrm{CORT}+\mathrm{EPI}$} & SAL & $514 \pm 27^{\#, \Omega}$ & $150 \pm 10^{\#, \Omega}$ & $94 \pm 7^{\Omega}$ & $70 \pm 5^{\Omega}$ & $79 \pm 6^{\#, \Omega}$ \\
\hline & $\mathrm{COC}$ & $460 \pm 26^{\#, \Omega}$ & $174 \pm 8^{\#, \Omega}$ & $131 \pm 9^{\#, \Omega}$ & $83 \pm 6^{\#, \Omega}$ & $88 \pm 8^{\#, \Omega}$ \\
\hline
\end{tabular}

Plasma corticosterone concentrations 30 min after treatment on days 1, 5, 9, 14, and 15. Animals were SHAM-operated or adrenalectomized (ADX), and ADX mice received either no substitution or replacement with corticosterone (cort), epinephrine (epi), or both (cort+epi). Mice received daily administrations of $15.0 \mathrm{mg} / \mathrm{kg}$ cocaine (COC) or saline (SAL; days 1-9), followed by a 5-day withdrawal interval, a saline challenge (day 14), and a $7.5 \mathrm{mg} / \mathrm{kg}$ cocaine challenge (day 15). Data are represented in average corticosterone (ng/ml) $\pm \mathrm{SEM}, n=6-11$ (saline) or $17-21$ (cocaine) animals/group

${ }^{*} p<0.001$ vs. SAL, ${ }^{\#}$ at least $\mathrm{p}<0.01$ vs. SHAM, ${ }^{\Omega}$ at least $p<0.05$ vs. ADX and ADXepi (LSD), ${ }^{\dagger} p<0.001$ vs. day 1 (paired $t$ test)

response can survive the post-treatment interval (De Jong et al. 2007; De Jong and De Kloet 2009).

In animals with corticosterone pellets (ADXcort and ADXcort+epi), hormone concentrations were elevated above SHAM levels on day $1(p<0.001)$ and thereafter gradually declined to on average $90 \mathrm{ng} / \mathrm{ml}$ on day 15 , being higher than in ADX and ADXepi mice $(p<0.05)$, but in the case of cocaine treatment, lower than in SHAM mice $(p<$ $0.01)$. On day 21 , there was no longer a difference between ADX animals substituted with or without corticosterone (data not shown). These data indicate that the subcutaneous corticosterone pellet generated plasma corticosterone concentrations that were very high on the first day of the treatment phase and thereafter declined to concentrations in the range of those induced by stress, which remained until the first cocaine challenge on day 15 .

\section{Discussion}

The major finding emerging from the present experiments is that in addition to corticosterone, epinephrine is necessary for sensitization to the locomotor stimulant effects of cocaine in DBA/2 mice. By contrast, neither corticosterone nor epinephrine alone were sufficient to reverse the deficit of ADX mice in psychomotor sensitization.

The present findings indicate that there is an interaction between the HPA-axis and the ANS in the regulation of the neuronal mechanism underlying behavioral sensitization to cocaine. The notion that adrenal glucocorticoids and catecholamines can interact to regulate behavior is supported by previous studies that describe both synergistic and antagonistic interactions, most notably in memory processing (Borrell et al. 1984; Roozendaal et al. 1996). We show that in the case of behavioral sensitization to cocaine, corticosterone and epinephrine cooperate. Furthermore, the results suggest that the cooperation between the two adrenal stress hormones occurs during initiation rather than expression of cocaine-induced behavioral sensitization in DBA/2 mice. ADX mice supplemented with either corticosterone, epinephrine, or both showed an increase in the locomotor response to cocaine between days 1 and 5, suggesting that either hormone promotes the development of sensitization during repeated cocaine treatment. However, presence of both hormones was necessary to achieve full restoration of the cocaine response to SHAM levels on day 5. Remarkably, replacement with corticosterone and/or epinephrine was not sufficient to restore the acute response to cocaine on day 1 . It is conceivable that the duration of the corticosteroid replacement was too short to achieve reversal of the ADX effect on day 1, as the hormone pellets were implanted one day prior to the first drug exposure.

In a previous study, we have observed that expression of sensitization is independent of glucocorticoids, as the glucocorticoid receptor (GR) antagonist mifepristone failed to block hyperresponsiveness to a drug challenge in animals that had previously acquired this behavior (De Jong and De Kloet 2009). The same holds true for epinephrine, as drug responses of mice receiving combined corticosterone and epinephrine replacement were maintained when epinephrine was omitted prior to the second cocaine challenge (day 21). The observation that by the time of the second cocaine challenge (day 21) drug responses of mice receiving chronic corticoste- 
rone mimicked those of SHAM mice suggests that while a certain degree of sensitization develops in mice receiving corticosterone, a longer withdrawal duration may be required for this behavior to become expressed. By contrast, mice substituted with only epinephrine did not show drug responses higher than of ADX mice on day 21. These findings suggest that of the two adrenal stress hormones, corticosterone plays the most critical role in behavioral sensitization to cocaine, whereas the primary effect of epinephrine is to facilitate the actions of the glucocorticoid. It can, however, not be excluded that the chronic corticosterone substitution also facilitated the responsiveness to an acute administration of cocaine. Further studies including additional control groups that are naive to cocaine until day 21 are required to address this issue. Furthermore, it is conceivable that during arousing tasks, such as behavioral testing, there is substantial norepinephrine release from sympathetic nerve terminals which may have facilitated the actions of corticosterone. In addition, druginduced norepinephrine release may sensitize with repeated cocaine administration, thereby contributing to the persistent hyperresponsiveness of mice having received both replacement therapies even when tested in the absence of epinephrine (day 21). There is indeed evidence for sensitization of norepinephrine release in the central nervous system associated with behavioral sensitization, which has been found to occur in both the hypothalamus and the nucleus accumbens (Schmidt et al. 2001; Vanderschuren et al. 1999). Nevertheless, the present finding of an interaction between the HPAaxis and the ANS in cocaine sensitization may explain part of the current controversy regarding the role of corticosterone in behavioral responsiveness to psychostimulants (Rivet et al. 1989; Badiani et al. 1995; Pauly et al. 1993).

Interestingly, after sensitization, a saline challenge was sufficient to induce a modest increase in locomotor activity and plasma corticosterone levels in SHAM animals (day 14). Although responses to the cocaine challenge on day 15 were significantly greater, this indicates that sensitization does not exclusively occur at a biochemical level in the motive system but that the expectation to receive cocaine in a given environment can induce these behavioral and endocrine effects in intact animals. There is indeed a great body of evidence demonstrating that drug-associated environments can act as an occasion setter for the expression of sensitization (reviewed in Badiani and Robinson 2004). A similar trend towards enhanced locomotor responsiveness to the saline challenge was found in mice substituted with corticosterone (ADX cort and ADXcort+epi) but not epinephrine alone, suggesting that corticosterone is the adrenal hormone that plays an important role in drug-induced conditioned locomotion, whereas epinephrine is not necessary for environmental conditioning in psychomotor sensitization.

It is not likely that higher, or perhaps lower, doses of epinephrine or corticosterone alone could be sufficient to fully restore the effects of cocaine. In pilot studies, we have investigated the effects of $5 \times 10^{-5}$ and $5 \times 10^{-2} \mathrm{mg} / \mathrm{kg}$ epinephrine. Whereas the lower dose did not affect cocaineinduced behavior, the higher dose gave similar results as observed in the present study (inefficacy of epinephrine alone and full reversal of sensitization in combination with corticosterone). With respect to corticosterone, a $20 \%$ corticosterone pellet has been demonstrated previously to fully restore amphetamine-induced locomotion in ADX mice (van den Buuse et al. 2004). Even higher doses of epinephrine and corticosterone were found to negatively affect the physical well-being of the animals and therefore not further pursued.

Behavioral sensitization to psychostimulant drugs is mediated by the mesocorticolimbic dopamine system and the neuronal circuitry it is embedded in (reviewed in Pierce and Kalivas 1997; Vanderschuren and Kalivas 2000). Corticosterone readily passes the blood-brain barrier and the GR is highly expressed throughout the motive circuit and the limbic system (Reul and De Kloet 1985; Fuxe et al. 1985; Harfstrand et al. 1986). Studies using brain-specific GR knockouts have shown that the impact of glucocorticoids on psychostimulant sensitivity and behavioral sensitization is mediated via the GR in the brain (Deroche-Gamonet et al. 2003; Izawa et al. 2006). Epinephrine, by contrast, is a polar substance that cannot cross the blood-brain barrier (WeilMalherbe et al. 1959). Exogenous epinephrine does, however, modulate a wide variety of brain functions (e.g., memory storage, cortical information processing, arousal, and attention), suggesting that the catecholamine influences the central nervous system indirectly. The most probable route is via the activation of vagal afferents to the nucleus of the solitary tract resulting in the activation of central noradrenergic signaling (Gold and van Buskirk 1978; Williams and McGaugh 1993; Roozendaal 2002; Miyashita and Williams 2006). In addition, it has been proposed that epinephrine may influence brain function by increasing glucose concentrations in the blood (Gold et al. 1986), although this view has been challenged (Gamaro et al. 1997).

To investigate the possible involvement of glucose, we have established a dose-response curve for the effects of wide dose range of epinephrine $\left(5 \times 10^{-1}, 10^{-2}, 10^{-3}\right.$, and $\left.10^{-5} \mathrm{mg} / \mathrm{kg}\right)$ on plasma glucose (data not shown). Whereas the two highest doses increased plasma glucose in a dose-dependent manner, this was not the case for the two lowest doses, including the one used in the present study $\left(5 \times 10^{-3} \mathrm{mg} / \mathrm{kg}\right)$. In addition, we have measured plasma glucose $30 \mathrm{~min}$ after drug treatment on test days $1,9,14$, and 15 of the sensitization paradigm and found no difference between epinephrine- and saline-substituted mice on any test day (data not shown). Similarly, combined corticosterone and epinephrine substitution did not affect plasma glucose levels when compared to saline substitution. These observations indicate that the dose of epinephrine that influences behavioral sensitization is 
devoid of a metabolic effect and therefore excludes the possibility that a change in glucose metabolism has contributed to the effects of epinephrine on behavioral sensitization.

We therefore hypothesize that the noradrenergic system mediates the effects of epinephrine on behavioral sensitization to cocaine. Noradrenergic signaling would then be expected to play a critical role in behavioral sensitization to psychostimulants, as epinephrine is rapidly secreted in response to these drugs (Lewander 1968; Chiueh and Kopin 1978). In support of this hypothesis, it has been shown that $\alpha-1$ adrenergic receptors play a role in cocaine- and amphetamine-induced locomotion, behavioral sensitization, and reward (Drouin et al. 2002a, b), although one study reported no effects of $\alpha$ and $\beta$-adrenergic receptor antagonists on behavioral sensitization to amphetamine or cocaine (Vanderschuren et al. 2003). The discrepancy between these studies is likely to have originated from differences in experimental procedures, such as, e.g., the doses of the psychostimulants (being considerably lower in the studies of Drouin et al.), the design of the sensitization paradigm, and the species and strain of animals used. With respect to the design of the sensitization paradigm, Drouin et al. used a context-dependent sensitization setup, whereas Vanderschuren et al. used a contextindependent one. In view of the role of noradrenergic neurotransmission in learning and memory processes, this might indicate that norepinephrine is particularly involved in the context-dependent aspects of psychomotor sensitization. Additional evidence for the role of norepinephrine in psychostimulant sensitization has come from a study by Salomon et al. (2006) suggesting that behavioral sensitization to amphetamine results from an uncoupling between noradrenergic and serotonergic signaling. Taken together, these studies point to a role for norepinephrine in psychostimulant sensitization, although it can of course not be concluded whether this represents an indirect effect of epinephrine, direct actions of cocaine on the norepinephrine transporter, or both. In further support of the present findings, it has been demonstrated that the adrenergic system plays a role in the interaction between stress and drug responsiveness, as $\alpha 2$-adrenoreceptor agonists block stressinduced reinstatement of cocaine, heroin, and alcohol seeking (Erb et al. 2000; Shaham et al. 2000; Le et al. 2005). An interesting avenue for further research would be to compare the role of epinephrine in responsiveness to drugs that differentially activate the peripheral and central catecholamine (epinephrine and norepinephrine) systems, such as, e.g., amphetamine and cocaine (Florin et al. 1994; Pan et al. 2007; Vanderschuren et al. 2003).

Several brain regions are likely to be involved in the interaction between norepinephrine and the mesocorticolimbic dopamine system, and the presence of GRs throughout the motive circuit suggests that glucocorticoids can modulate this interaction at multiple levels. Evidence exists that direct noradrenergic innervation of the ventral tegmental area regulates dopamine release in the terminal regions of these neurons (nucleus accumbens, prefrontal cortex; Pan et al. 1996; Ihalainen and Tanila 2004). The amygdala is an area of interest, as norepinephrine in this region is of critical importance for the beneficial effects of both epinephrine and corticosterone on memory consolidation (Liang et al. 1986, 1995; Quirarte et al. 1997; Roozendaal et al. 2006) and the amygdala provides excitatory input to the mesocorticolimbic dopamine system (Robinson and Beart 1988). Furthermore, norepinephrine in the prefrontal cortex regulates amphetamine-induced reward, locomotion, and mesoaccumbens dopamine release (Blanc et al. 1994; Darracq et al. 1998; Ventura et al. 2003; Steketee 2003), and the excitatory corticofugal projections from the prefrontal cortex to the dopamine system are under the control of adrenergic innervation (Marek and Aghajanian 1999; Kovacs and Hernadi 2003). Finally, the hippocampus, receiving prominent noradrenergic innervation (Loy et al. 1980), plays a role in the acute reinforcing effects of drugs and in relapse to drug taking and also provides excitatory input into the midbrain dopaminergic neurons (Floresco et al. 2001).

In summary, the present data show that both the HPA-axis and the ANS play a crucial role in long-term behavioral sensitization to cocaine. This is an important finding since numerous investigations have been dedicated to the role of the HPA-axis in psychostimulant sensitization and reward, whereas the ANS has hardly gained any attention. Further characterization of the relationship between glucocorticoids, epinephrine, and psychostimulant responsiveness will lead to a better understanding of the mechanisms that underlie the effects of stress on drug addiction.

Acknowledgments This research was supported by NWO/INSERM/ ZON grants 985-10-014 and 985-10-504 and by the Royal Netherlands Academy of Arts and Sciences. We gratefully acknowledge S. Lachize and Ing. M. van der Mark for technical support and Dr. O.C. Meijer for critically reading the manuscript.

There are no conflicts of interest in relation to this manuscript. Inge E.M. de Jong, PhD. is currently employed by H. Lundbeck A/S. E.R. de Kloet is on the Scientific Advisory Board of Corcept Therapeutics Inc. and owns stocks of Corcept, is consultant of Organon International and has a joined research project with $\mathrm{H}$. Lundbeck A/S supported through Topinstitute Pharma, The Netherlands. The experiments comply with the current laws of the Netherlands.

Open Access This article is distributed under the terms of the Creative Commons Attribution Noncommercial License which permits any noncommercial use, distribution, and reproduction in any medium, provided the original author(s) and source are credited. 


\section{References}

Badiani A, Robinson TE (2004) Drug-induced neurobehavioral plasticity: the role of environmental context. Behav Pharmacol 15:327-339

Badiani A, Morano MI, Akil H, Robinson TE (1995) Circulating adrenal hormones are not necessary for the development of sensitization to the psychomotor activating effects of amphetamine. Brain Res 673:13-24

Blanc G, Trovero F, Vezina P, Herve D, Godeheu AM, Glowinski J, Tassin JP (1994) Blockade of prefronto-cortical alpha 1 -adrenergic receptors prevents locomotor hyperactivity induced by subcortical D-amphetamine injection. Eur J Neurosci 6:293298

Borrell J, De Kloet ER, Versteeg DH, Bohus B (1983) Inhibitory avoidance deficit following short-term adrenalectomy in the rat: the role of adrenal catecholamines. Behav Neural Biol 39:241258

Borrell J, De Kloet ER, Bohus B (1984) Corticosterone decreases the efficacy of adrenaline to affect passive avoidance retention of adrenalectomized rats. Life Sci 34:99-104

Cabib S, Orsini C, Le Moal M, Piazza PV (2000) Abolition and reversal of strain differences in behavioral responses to drugs of abuse after a brief experience. Science 289:463-465

Chiueh CC, Kopin IJ (1978) Centrally mediated release by cocaine of endogenous epinephrine and norepinephrine from the sympathoadrenal medullary system of unanesthetized rats. J Pharmacol Exp Ther 205:148-154

Darracq L, Blanc G, Glowinski J, Tassin JP (1998) Importance of the noradrenaline-dopamine coupling in the locomotor activating effects of D-amphetamine. J Neurosci 18:2729-2739

De Jong IEM, De Kloet ER (2004) Glucocorticoids and vulnerability to psychostimulant drugs: toward substrate and mechanism. Ann N Y Acad Sci 1018:192-198

De Jong IEM, De Kloet ER (2009) Critical time-window for the actions of adrenal glucocorticoids in behavioural sensitisation to cocaine. Eur J Pharmacol 604:66-73

De Jong IEM, Oitzl MS, de Kloet ER (2007) Adrenalectomy prevents behavioural sensitisation of mice to cocaine in a genotypedependent manner. Behav Brain Res 177:329-339

De Kloet ER, Joels M, Holsboer F (2005) Stress and the brain: from adaptation to disease. Nat Rev Neurosci 6:463-475

Der-Avakian A, Bland ST, Schmid MJ, Watkins LR, Spencer RL, Maier SF (2006) The role of glucocorticoids in the uncontrollable stress-induced potentiation of nucleus accumbens shell dopamine and conditioned place preference responses to morphine. Psychoneuroendocrinology 31:653-663

Deroche V, Marinelli M, Maccari S, Le Moal M, Simon H, Piazza PV (1995) Stress-induced sensitization and glucocorticoids. I. Sensitization of dopamine-dependent locomotor effects of amphetamine and morphine depends on stress-induced corticosterone secretion. J Neurosci 15:7181-7188

Deroche-Gamonet V, Sillaber I, Aouizerate B, Izawa R, Jaber M, Ghozland S, Kellendonk C, Le Moal M, Spanagel R, Schutz G, Tronche F, Piazza PV (2003) The glucocorticoid receptor as a potential target to reduce cocaine abuse. J Neurosci 23: $4785-4790$

Drouin C, Blanc G, Villegier AS, Glowinski J, Tassin JP (2002a) Critical role of alpha1-adrenergic receptors in acute and sensitized locomotor effects of D-amphetamine, cocaine, and GBR 12783: influence of preexposure conditions and pharmacological characteristics. Synapse 43:51-61
Drouin C, Darracq L, Trovero F, Blanc G, Glowinski J, Cotecchia S, Tassin JP (2002b) Alphalb-adrenergic receptors control locomotor and rewarding effects of psychostimulants and opiates. J Neurosci 22:2873-2884

Erb S, Hitchcott PK, Rajabi H, Mueller D, Shaham Y, Stewart J (2000) Alpha-2 adrenergic receptor agonists block stress-induced reinstatement of cocaine seeking. Neuropsychopharmacology $23: 138-150$

Floresco SB, Todd CL, Grace AA (2001) Glutamatergic afferents from the hippocampus to the nucleus accumbens regulate activity of ventral tegmental area dopamine neurons. J Neurosci 21:4915-4922

Florin SM, Kuczenski R, Segal RS (1994) Regional extracellular norepinephrine responses to amphetamine and cocaine and effects of clonidine pretreatment. Brain Res 654:53-62

Fuxe K, Wikstrom AC, Okret S, Agnati LF, Harfstrand A, Yu ZY, Granholm L, Zoli M, Vale W, Gustafsson et al (1985) Mapping of glucocorticoid receptor immunoreactive neurons in the rat tel- and diencephalon using a monoclonal antibody against rat liver glucocorticoid receptor. Endocrinology 117: $1803-1812$

Gamaro GD, Denardin JD Jr., Michalowski MB, Catelli D, Correa JB, Xavier MH, Dalmaz C (1997) Epinephrine effects on memory are not dependent on hepatic glucose release. Neurobiol Learn Mem 68:221-229

Goeders NE (2002) The HPA axis and cocaine reinforcement. Psychoneuroendocrinology 27:13-33

Goeders NE (2003) The impact of stress on addiction. Eur Neuropsychopharmacol 13:435-441

Goeders NE, Guerin GF (1994) Non-contingent electric footshock facilitates the acquisition of intravenous cocaine self-administration in rats. Psychopharmacology (Berl) 114:63-70

Gold PE, Van Buskirk RB (1975) Facilitation of time-dependent memory processes with posttrial epinephrine injections. Behav Biol 13:145-153

Gold PE, van Buskirk R (1978) Posttraining brain norepinephrine concentrations: correlation with retention performance of avoidance training and with peripheral epinephrine modulation of memory processing. Behav Biol 23:509-520

Gold PE, Vogt J, Hall JL (1986) Glucose effects on memory: behavioral and pharmacological characteristics. Behav Neural Biol 46:145-155

Haile CN, GrandPre T, Kosten TA (2001) Chronic unpredictable stress, but not chronic predictable stress, enhances the sensitivity to the behavioral effects of cocaine in rats. Psychopharmacology (Berl) 154:213-220

Haney M, Maccari S, Le Moal M, Simon H, Piazza PV (1995) Social stress increases the acquisition of cocaine self-administration in male and female rats. Brain Res 698:46-52

Harfstrand A, Fuxe K, Cintra A, Agnati LF, Zini I, Wikstrom AC, Okret S, Yu ZY, Goldstein M, Steinbusch H (1986) Glucocorticoid receptor immunoreactivity in monoaminergic neurons of rat brain. Proc Natl Acad Sci USA 83:9779-9783

Herman JP, Stinus L, Le Moal M (1984) Repeated stress increases locomotor response to amphetamine. Psychopharmacology (Berl) 84:431-435

Ihalainen JA, Tanila H (2004) In vivo regulation of dopamine and noradrenaline release by alpha2A-adrenoceptors in the mouse nucleus accumbens. J Neurochem 91:49-56

Izawa R, Jaber M, Deroche-Gamonet V, Sillaber I, Kellendonk C, Le Moal M, Tronche F, Piazza PV (2006) Gene expression regulation following behavioral sensitization to cocaine in transgenic mice lacking the glucocorticoid receptor in the brain. Neuroscience 137:915-924 
Kovacs P, Hernadi I (2003) Alpha2 antagonist yohimbine suppresses maintained firing of rat prefrontal neurons in vivo. Neuroreport 14:833-836

Le AD, Harding S, Juzytsch W, Funk D, Shaham Y (2005) Role of alpha-2 adrenoceptors in stress-induced reinstatement of alcohol seeking and alcohol self-administration in rats. Psychopharmacology (Berl) 179:366-373

Lepsch LB, Gonzalo LA, Magro FJ, Delucia R, Scavone C, Planeta CS (2005) Exposure to chronic stress increases the locomotor response to cocaine and the basal levels of corticosterone in adolescent rats. Addict Biol 10:251-256

Lewander T (1968) Effects of amphetamine on urinary and tissue catecholamines in rats after inhibition of its metabolism with desmethylimipramine. Eur J Pharmacol 5:1-9

Liang KC, Juler RG, McGaugh JL (1986) Modulating effects of posttraining epinephrine on memory: involvement of the amygdala noradrenergic system. Brain Res 368:125-133

Liang KC, Chen LL, Huang TE (1995) The role of amygdala norepinephrine in memory formation: involvement in the memory enhancing effect of peripheral epinephrine. Chin J Physiol 38:81-91

Loy R, Koziell DA, Lindsey JD, Moore RY (1980) Noradrenergic innervation of the adult rat hippocampal formation. J Comp Neurol 189:699-710

Mantsch JR, Katz ES (2007) Elevation of glucocorticoids is necessary but not sufficient for the escalation of cocaine self-administration by chronic electric footshock stress in rats. Neuropsychopharmacology 32:367-376

Marek GJ, Aghajanian GK (1999) 5-HT2A receptor or alpha1adrenoceptor activation induces excitatory postsynaptic currents in layer $\mathrm{V}$ pyramidal cells of the medial prefrontal cortex. Eur $\mathrm{J}$ Pharmacol 367:197-206

Marinelli M, Piazza PV (2002) Interaction between glucocorticoid hormones, stress and psychostimulant drugs. Eur J Neurosci 16:387-394

Miyashita T, Williams CL (2006) Epinephrine administration increases neural impulses propagated along the vagus nerve: role of peripheral beta-adrenergic receptors. Neurobiol Learn Mem 85:116-124

Pan WH, Sung JC, Fuh SM (1996) Locally application of amphetamine into the ventral tegmental area enhances dopamine release in the nucleus accumbens and the medial prefrontal cortex through noradrenergic neurotransmission. J Pharmacol Exp Ther 278:725-731

Pan WH, Hsieh MC, Wu HH, Lin SK (2007) Difference in magnitude of psychostimulant-induced extracellular norepinephrine in the ventral tegmental area contributes to discrepant prefrontal dopamine outflow. Addict Biol 12:51-58

Pauly JR, Robinson SF, Collins AC (1993) Chronic corticosterone administration enhances behavioral sensitization to amphetamine in mice. Brain Res 620:195-202

Piazza PV, Le Moal ML (1996) Pathophysiological basis of vulnerability to drug abuse: role of an interaction between stress, glucocorticoids, and dopaminergic neurons. Annu Rev Pharmacol Toxicol 36:359-378

Piazza PV, Le Moal M (1998) The role of stress in drug selfadministration. Trends Pharmacol Sci 19:67-74

Piazza PV, Deminiere JM, Le Moal M, Simon H (1990) Stress- and pharmacologically-induced behavioral sensitization increases vulnerability to acquisition of amphetamine self-administration. Brain Res 514:22-26

Pierce RC, Kalivas PW (1997) A circuitry model of the expression of behavioral sensitization to amphetamine-like psychostimulants. Brain Res Brain Res Rev 25:192-216

Prasad BM, Ulibarri C, Kalivas PW, Sorg BA (1996) Effect of adrenalectomy on the initiation and expression of cocaineinduced sensitization. Psychopharmacology (Berl) 125:265-273
Przegalinski E, Filip M, Siwanowicz J, Nowak E (2000) Effect of adrenalectomy and corticosterone on cocaine-induced sensitization in rats. J Physiol Pharmacol 51:193-204

Quirarte GL, Roozendaal B, McGaugh JL (1997) Glucocorticoid enhancement of memory storage involves noradrenergic activation in the basolateral amygdala. Proc Natl Acad Sci USA 94:14048-14053

Reul JM, De Kloet ER (1985) Two receptor systems for corticosterone in rat brain: microdistribution and differential occupation. Endocrinology 117:2505-2511

Rivet JM, Stinus L, LeMoal M, Mormede P (1989) Behavioral sensitization to amphetamine is dependent on corticosteroid receptor activation. Brain Res 498:149-153

Robinson TG, Beart PM (1988) Excitant amino acid projections from rat amygdala and thalamus to nucleus accumbens. Brain Res Bull $20: 467-471$

Roozendaal B (2002) Stress and memory: opposing effects of glucocorticoids on memory consolidation and memory retrieval. Neurobiol Learn Mem 78:578-595

Roozendaal B, Carmi O, McGaugh JL (1996) Adrenocortical suppression blocks the memory-enhancing effects of amphetamine and epinephrine. Proc Natl Acad Sci USA 93:1429-1433

Roozendaal B, Okuda S, Van der Zee EA, McGaugh JL (2006) Glucocorticoid enhancement of memory requires arousal-induced noradrenergic activation in the basolateral amygdala. Proc Natl Acad Sci USA 103:6741-6746

Salomon L, Lanteri C, Glowinski J, Tassin JP (2006) Behavioral sensitization to amphetamine results from an uncoupling between noradrenergic and serotonergic neurons. Proc Natl Acad Sci USA 103:7476-7481

Schmidt ED, Tilders FJ, Binnekade R, Schoffelmeer AN, De Vries TJ (1999) Stressor- or drug-induced sensitization of the corticosterone response is not critically involved in the long-term expression of behavioural sensitization to amphetamine. Neuroscience 92:343-352

Schmidt ED, Schoffelmeer AN, De Vries TJ, Wardeh G, Dogterom G, Bol JG, Binnekade R, Tilders FJ (2001) A single administration of interleukin-1 or amphetamine induces long-lasting increases in evoked noradrenaline release in the hypothalamus and sensitization of $\mathrm{ACTH}$ and corticosterone responses in rats. Eur $\mathrm{J}$ Neurosci 13:1923-1930

Shaham Y, Highfield D, Delfs J, Leung S, Stewart J (2000) Clonidine blocks stress-induced reinstatement of heroin seeking in rats: an effect independent of locus coeruleus noradrenergic neurons. Eur J Neurosci 12:292-302

Sorg BA, Kalivas PW (1991) Effects of cocaine and footshock stress on extracellular dopamine levels in the ventral striatum. Brain Res 559:29-36

Steketee JD (2003) Neurotransmitter systems of the medial prefrontal cortex: potential role in sensitization to psychostimulants. Brain Res Brain Res Rev 41:203-228

Sternberg DB, Isaacs KR, Gold PE, McGaugh JL (1985) Epinephrine facilitation of appetitive learning: attenuation with adrenergic receptor antagonists. Behav Neural Biol 44:447-453

Tidey JW, Miczek KA (1997) Acquisition of cocaine selfadministration after social stress: role of accumbens dopamine. Psychopharmacology (Berl) 130:203-212

Van den Buuse M, Morris M, Chavez C, Martin S, Wang J (2004) Effect of adrenalectomy and corticosterone replacement on prepulse inhibition and locomotor activity in mice. Br J Pharmacol 142:543-550

Vanderschuren LJ, Kalivas PW (2000) Alterations in dopaminergic and glutamatergic transmission in the induction and expression of behavioral sensitization: a critical review of preclinical studies. Psychopharmacology (Berl) 151:99-120

Vanderschuren LJ, Wardeh G, De Vries TJ, Mulder AH, Schoffelmeer AN (1999) Opposing role of dopamine D1 and D2 receptors in 
modulation of rat nucleus accumbens noradrenaline release. J Neurosci 19:4123-4131

Vanderschuren LJ, Beemster P, Schoffelmeer AN (2003) On the role of noradrenaline in psychostimulant-induced psychomotor activity and sensitization. Psychopharmacology (Berl) 169:176-185

Ventura R, Cabib S, Alcaro A, Orsini C, Puglisi-Allegra S (2003)

Norepinephrine in the prefrontal cortex is critical for amphetamine- induced reward and mesoaccumbens dopamine release. J Neurosci 23:1879-1885

Weil-Malherbe H, Axelrod J, Tomchick R (1959) Blood-brain barrier for adrenaline. Science 129:1226-1227

Williams CL, McGaugh JL (1993) Reversible lesions of the nucleus of the solitary tract attenuate the memory-modulating effects of posttraining epinephrine. Behav Neurosci 107:955-962 